\title{
A EFETIVAÇÃO DOS DIREITOS HUMANOS NA CONCEPÇÃO MULTICULTURAL: CONSTRUÇÃO DA CIDADANIA COSMOPOLITA
}

\author{
THE EFFECTIVE HUMAN RIGHTS IN MULTICULTURAL DESIGN: \\ CONSTRUCTION OF CITIZENSHIP COSMOPOLITAN
}

\begin{abstract}
CRISNA MARIA MULLER
Mestranda em Ciências Sociais Aplicadas pela Universidade Estadual de Ponta Grossa (UEPG/PR), pesquisadora do Núcleo Temático de Pesquisa em Estado, Políticas Públicas e Práticas Sociais (UEPG). Graduada em Direito pela Universidade do Oeste de Santa Catarina (UNOESC). crisnamm@yahoo.com.br
\end{abstract}

DIRCEIA MOREIRA

Doutora em Direito pela Pontifícia Universidade Católica de São Paulo ( PUC/SP). Atualmente é professora da Universidade Estadual de Ponta Grossa (UEPG/PR), nos cursos de graduação e pós-graduação (mestrado e doutorado) em Ciências Sociais Aplicadas. dirceia@dirceiam.com.br

\begin{abstract}
RESUMO
O presente artigo objetiva investigar a imposição do discurso hegemônico ocidental dos direitos humanos em âmbito global a favor do interesse econômicoliberal. Ademais, pretende aprofundar a construção de um discurso contra-hegemônico dos direitos humanos, com aporte multicultural, além de delinear os elementos da cidadania cosmopolita, que se desenvolvem no espaço de encontro entre as diversas culturas e agentes de mudança. Para atingir os objetivos propostos, o estudo aplicou o método hermenêutico e o procedimento de pesquisa documental e bibliográfica. As conclusões apontam que o discurso hegemônico liberal dos direitos humanos expõe suas limitações ao se apresentar como caminho de emancipação do ser humano global. Assim, somente por um tipo de hermenêutica contrahegemônica é que os direitos humanos poderão se efetivar como política cosmopolita.
\end{abstract}

Palavras-chave: Cidadania cosmopolita; Direitos Humanos; Multiculturalismo.

\begin{abstract}
This article investigates the imposition of Western hegemonic discourse of human rights globally in favor of economic and liberal interest. Furthermore, we intend to deepen the construction of a counterhegemonic discourse of human rights, multicultural contribution and outlines the elements of cosmopolitan citizenship, which develop within encounter between different cultures and change agents. To achieve the proposed objectives, the study applied the inductive method and the search procedure documentary and literature. The findings indicate that the liberal hegemonic discourse of human rights exposes its limitations presenting himself as the be global human emancipation path. Thus, only by a kind of counter-hegemonic hermeneutics is that human rights can be effective as cosmopolitan politics.
\end{abstract}

Keywords: Cosmopolitan citizenship; Human rights; Multiculturalism. 


\section{SUMÁRIO}

1 PERCURSO HISTÒRICO DOS DIREITOS HUMANOS; 2 APROPRIAÇÃO OCIDENTAL DO DISCURSO DOS DIREITOS HUMANOS E UMA NOVA HERMENEUTICA DE SUPERAÇÃO NA PERSPECTIVA DA CONSTRUÇÃO DA CIDADANIA COSMOPOLITA; CONCLUSÃO; REFERÊNCIAS.

\section{INTRODUÇÃO}

O presente estudo engloba, na delimitação do tema, três assuntos que são alvo de discussão nas mais diversas áreas das Ciências Sociais Aplicadas e Ciências Humanas, tendo em vista a transdisciplinaridade dos mesmos: os direitos humanos, o multiculturalismo e a cidadania, a respeito dos quais despontam investigações teóricas que auxiliam na compreensão da realidade e da indicação de perspectivas globais.

No cenário da profunda reconstituição da ordem internacional Pós-Segunda Guerra Mundial e sob os impactos da catástrofe moral que representou a experiência do totalitarismo nazista, desencadeou-se, a partir da Declaração Universal proclamada pela Organização das Nações Unidas-ONU, em 1948, um processo sem precedentes de internacionalização do reconhecimento, proteção e promoção dos direitos humanos. Desde então, é considerável o registro de documentos, de caráter internacional, que proclamam sua defesa e assentam os direitos humanos no mundo contemporâneo.

Contudo, o objetivo dos direitos humanos, inicialmente de resistência à dominação, sofreu uma apropriação ocidental, onde estes direitos assumem a posição hegemônica de ideologia conciliadora, capaz de unir e legitimar, através de seu discurso, os mais distintos interesses.

Assim, problematizando a conjuntura, como a construção da cidadania cosmopolita, poderá se apresentar como um contraponto à imposição do discurso hegemônico liberal dos direitos humanos que já não encontra, nas diferentes regiões do globo, uma realização em larga escala.

Neste contexto, pretende-se investigar, a partir da compreensão do percurso histórico, a imposição do discurso hegemônico ocidental dos direitos humanos no âmbito global e sua aplicação a favor do interesse econômico-liberal. Ademais, aprofundar-se-á a construção de um discurso contra-hegemônico dos direitos humanos, com aporte multicultural, além de delinear os elementos da cidadania cosmopolita. 


\section{每

A EFETIVAÇÃO DOS DIREITOS HUMANOS NA CONCEPÇÃO MULTICULTURAL: CONSTRUÇÃO DA CIDADANIA COSMOPOLITA

A contribuição desse trabalho reside na reflexão teórica acerca da nova regra hermenêutica que tenha por perspectiva a construção da cidadania cosmopolita, assentada num mínimo ético que garanta que os direitos humanos se efetivem nas e a partir das diferentes culturas.

Quanto à metodologia, no intuito de atender os objetivos propostos neste estudo, lançarse-á mão do método interpretativo hermenêutico e do procedimento de pesquisa documental e bibliográfica.

\section{PERCURSO HISTÓRICO DOS DIREITOS HUMANOS}

O conceito de humanidade é uma invenção da modernidade. Em largos passos históricos, nota-se que na Grécia Antiga e em Roma existiam os cidadãos, mas não os homens, no sentido de membros da espécie humana. 0 universalismo e a igualdade espiritual foram introduzidos pela declaração do apóstolo São Paulo, de que não há grego ou judeu, homem ou mulher, homem livre ou escrava, afirmação registrada na Epístola aos Gálatas 3,28. ${ }^{1}$

Em 1550, o significado de humanidade foi rigorosamente contestado em um dos mais importantes debates da história, quando Charles V da Espanha convocou um conselho de Estado em Valladolid para discutir a atitude espanhola com relação aos indígenas do México. Do debate entre o filósofo Sepulveda e o Bispo Bartholomé de las Casas, segundo Costas Douzinas² ${ }^{2}$, capturase a ideologia dominante dos impérios, imperialismos e colonialismos ocidentais, que justifica a escravidão, as atrocidades e até mesmo a aniquilação como estratégias da missão civilizatória.

Sobreveio a Declaração Francesa dos Direitos do Homem e do Cidadão de 1789, manifesto político da modernidade, que no seu art. $1^{\circ}$ afirma: “os homens nascem e permanecem livres e iguais em direitos"3.

Porém, a Declaração não especificou a proteção de grupos particulares, como as classes sociais e econômicas, as religiões, e o gênero a quem se destinava, assim, o homem dos direitos

\footnotetext{
${ }^{1}$ DOUZINAS, Costas. O paradoxo dos direitos humanos. Tradução de Caius Brandão. In: Pensar os Direitos Humanos: desafios à educação nas sociedades democráticas. Anuário do Núcleo Interdisciplinar de Estudos e Pesquisa em Direitos Humanos - UFG. Vol.1. n. 1, 2011.

2 DOUZINAS, Costas. 0 paradoxo dos direitos humanos. Tradução de Caius Brandão. In: Pensar os Direitos Humanos: desafios à educação nas sociedades democráticas. Anuário do Núcleo Interdisciplinar de Estudos e Pesquisa em Direitos Humanos - UFG. Vol.1. n. 1, 2011.

3 Declaração Francesa dos Direitos do Homem e do Cidadão de 1789. Disponível em http: <http://pfdc.pgr.mpf.mp.br/atuacao-e-conteudos-de-apoio/legislacao/direitoshumanos/declar_dir_homem_cidadao.pdf >. Acesso em: 10 mar.2016.
} 


\section{每

A EFETIVAÇÃO DOS DIREITOS HUMANOS NA CONCEPÇÃO MULTICULTURAL: CONSTRUÇÃO DA CIDADANIA COSMOPOLITA

CRISNA MARIA MULLER DIRCEIA MOREIRA

humanos não possui características concretas, cor, sexo ou história. Por tal razão, Douzinas ${ }^{4}$ afirma que este documento afirmou o nacionalismo, haja vista que o homem que realmente desfrutava dos direitos era o cidadão nacional e, na maioria das vezes, aquele do sexo masculino, branco e com poder aquisitivo, com exclusão dos demais.

Neste viés, a Declaração de 1789 anunciou, sim, a mudança de ângulo na relação política entre soberano e súdito e entre Estado e cidadão. No campo do direito, passou-se da enunciação dos deveres dos súditos à positivação dos direitos do cidadão. Além de afirmar os direitos dos cidadãos, passou a definir como dever do Estado a sua proteção. A Declaração defendeu princípios anti-históricos ao dizer que os homens nascem livres e iguais, pois, afinal, todas as estruturas sociais naquele momento, a começar pela família, mostravam relações desiguais e hierarquicamente estabelecidas. Enfim, o homem a que se refere a Revolução Francesa não era um homem universal, mas sim o homem burguês. ${ }^{5}$

Somente com a Declaração Universal dos Direitos do Homem de 1948, aprovada após a tragédia da Segunda Guerra Mundial, é que ocorre a internacionalização dos direitos do homem, a ampliação do campo de validade dos Estados particulares para o sistema internacional, onde se busca a proteção dos direitos do homem fora e dentro dos Estados particulares, ou seja, nascem os titulares de uma nova cidadania, a mundial. ${ }^{6}$

Os direitos naturais só foram reabilitados durante o julgamento de Nuremberg dos criminosos de guerra nazistas, sob a nova forma de direitos humanos. Os juízes aliados foram confrontados com uma defesa legalmente convincente. Os réus alemães haviam seguido as leis nazistas e agiram dentro dos limites da lei do estado, a única lei válida de acordo com a ortodoxia corrente. Para lidar com essa questão, o tribunal argumentou de forma criativa que o extermínio sistemático de judeus e outros violou o direito consuetudinário e os princípios das nações civilizadas. Ao fazê-lo, o tribunal redescobriu os princípios do direito natural: sua insistência que uma hierarquia de leis existe e que, independentemente da situação do direito interno, os princípios jurídicos universais prevalecem. A escravidão, o extermínio das populações indígenas e as atrocidades coloniais tinham sido repetidamente cometidos pelo Ocidente. Agora, porém, que os europeus haviam tentado exterminar outros europeus, o conceito de 'crimes contra a humanidade' entrou no léxico jurídico. A humanidade foi dividida em vítimas e agressores. Depois de 1945, reconhecemos tardiamente que a

\footnotetext{
${ }^{4}$ DOUZINAS, Costas. 0 paradoxo dos direitos humanos. Tradução de Caius Brandão. In: Pensar os Direitos Humanos: desafios à educação nas sociedades democráticas. Anuário do Núcleo Interdisciplinar de Estudos e Pesquisa em Direitos Humanos - UFG. Vol.1. n. 1, 2011.

${ }^{5}$ BOBBIO, Norberto. A era dos direitos. Tradução de Carlos Nelson Coutinho. Rio de Janeiro: Campus, 2004.

${ }^{6}$ BOBBIO, Norberto. A era dos direitos. Tradução de Carlos Nelson Coutinho. Rio de Janeiro: Campus, 2004.
} 
A EFETIVAÇÃO DOS DIREITOS HUMANOS NA CONCEPÇÃO MULTICULTURAL: CONSTRUÇÃO DA CIDADANIA COSMOPOLITA

humanidade é o anjo exterminador de si mesmo. Em resposta, Nuremberg e a Declaração Universal de 1948 iniciaram um enorme processo internacional de definição de padrões. ${ }^{7}$

Desta forma, a internacionalização dos direitos humanos é um movimento recente na história, que surgiu após as barbáries do totalitarismo. A reconstrução e proteção dos direitos humanos como paradigma e referencial ético a orientar a ordem internacional, segundo Piovesan (2007), não pode ser reduzido ao âmbito doméstico de um Estado, pois se revela tema de interesse internacional.

Por direitos humanos se entendem aquelas posições jurídicas que reconhecem a proteção de certos valores e reivindicações essenciais ao ser humano, independentemente de sua vinculação com determinada ordem constitucional. ${ }^{8}$

Norberto Bobbio sintetiza os direitos humanos a partir de três teses fundamentais, ao afirmar que os direitos humanos não são naturais e sim direitos históricos, que eles surgem no início da era moderna e podem ser entendidos como indicadores de avanço histórico. Ademais, ao reconhecer o percurso histórico da construção social dos direitos humanos, lança luzes sobre a emergência das novas demandas acerca dos direitos e dos critérios de cidadania. ${ }^{9}$

\section{APROPRIAÇÃO OCIDENTAL DO DISCURSO DOS DIREITOS HUMANOS E UMA NOVA HERMENEUTICA DE SUPERAÇÃO NA PERSPECTIVA DA CONSTRUÇÃO DA CIDADANIA COSMOPOLITA}

A partir de 1948, ano da Declaração Universal dos Direitos do Homem, ocorre um aumento no número de documentos legais que prevêem a defesa e a proteção dos direitos humanos, como a Declaração sobre o Direito ao Desenvolvimento, a Convenção sobre os Direitos da Criança, a Convenção sobre a Eliminação de Todas as Formas de Discriminação contra a Mulher, a Convenção Internacional sobre a Eliminação de Todas as Formas de Discriminação Racial, o Pacto Internacional de Direitos Civis e Políticos, o Pacto Internacional de Direitos Econômicos, Sociais e Culturais e a Convenção contra a Tortura e Outros Tratamentos ou Penas

\footnotetext{
${ }^{7}$ DOUZINAS, Costas. O Fim dos Direitos Humanos. São Leopoldo: UNISINOS, 2009. p. 8-9.

8 SARLET, Ingo Wolfgang. A eficácia dos direitos fundamentais. 10. ed. Porto Alegre: Livraria do Advogado, 2008.

${ }^{9}$ BOBBIO, Norberto. A era dos direitos. Tradução de Carlos Nelson Coutinho. Rio de Janeiro: Campus, 2004.
} 
A EFETIVAÇÃO DOS DIREITOS HUMANOS NA CONCEPÇÃO MULTICULTURAL: CONSTRUÇÃO DA CIDADANIA COSMOPOLITA

CRISNA MARIA MULLER DIRCEIA MOREIRA

Cruéis, Desumanos ou Degradantes. Assim, a existência do sistema internacional de proteção demonstra a importância alcançada pelos direitos humanos no mundo contemporâneo.

Contudo, alguns autores dentre eles, Boaventura de Sousa Santos e Costas Douzinas, apontam para a apropriação liberal e ocidental do discurso dos direitos humanos, que os colocam a serviço dos interesses econômicos e geopolíticos dos Estados capitalistas hegemônicos.

Boaventura aponta a presença da marca ocidental liberal do discurso dominante dos direitos humanos na própria Declaração Universal de 1948, haja vista que foi elaborada sem a participação da maioria dos povos do mundo, reconheceu exclusivamente direitos individuais, com exceção do direito coletivo à autodeterminação, o qual, no entanto, foi restringido aos povos subjugados pelo colonialismo europeu; concedeu prioridade aos direitos cívicos e políticos sobre os direitos econômicos, sociais e culturais e no reconhecimento do direito de propriedade como o primeiro e, durante muitos anos, o único direito econômico. ${ }^{10}$

Ademais, o emprego encantado da política de direitos humanos permitiu atrocidades indescritíveis contra a humanidade e que foram avaliados com duplicidade de critérios de invisibilidade e visibilidade ${ }^{11}$. Neste sentido, registra-se o ataque americano ao Iraque (20032011) no qual as violações aos direitos humanos em andamento naquele país foram propositalmente divulgadas no intuito de justificar as intervenções militares, outro exemplo é o contexto de perseguição e retaliação empreendido pelo governo norte-americano, após o ataque ao Wold Trade Center, aos soldados afegãos capturados na guerra subseqüente, violando seus direitos, abrindo uma campanha global contra os inimigos demonizados, sem cogitar a possibilidade de estas ações serem justificadas e repreendidas pela lei internacional ${ }^{12}$.

Acerca desta interferência ocidental o jurista grego, Costas Douzinas, observa que ela ocorre, na maioria das vezes, nos países mais pobres e as escolhas de como e quem ajudar são feitas estrategicamente. Afirma ser até banal o diagnóstico de que desde 1945 as intervenções internacionais nunca foram levadas à Europa ocidental ou aos EUA, tampouco a responsabilidade

\footnotetext{
10 SANTOS, Boaventura de Sousa. Uma concepção multicultural de Direitos Humanos. Contexto Internacional,Rio de Janeiro, vol.23, jan/jun, 2001

11 SANTOS, Boaventura de Sousa. Uma concepção multicultural de Direitos Humanos. Contexto Internacional, Rio de Janeiro, vol.23, jan/jun, 2001.

12 VIEIRA, Oscar Vilhena. Reflexões acerca da sociedade civil e dos direitos humanos. Conectas Direitos Humanos: São Paulo. Ed. v. 1, n. 1, Jan/2004. Disponível em: < http://www.conectas.org/pt/acoes/sur/edicao/1/1000229-reflexoes-acerca-da-sociedade-civil-e-dosdireitos-humanos>. Acesso em: 15 mar. 2016.
} 


\section{每

A EFETIVAÇÃO DOS DIREITOS HUMANOS NA CONCEPÇÃO MULTICULTURAL: CONSTRUÇÃO DA CIDADANIA COSMOPOLITA

internacional de proteger os povos foi evocada contra um aliado do Ocidente, ou seja, o mau é sempre o outro, distante do mundo "civilizado" ocidental. ${ }^{13}$

Costas Douzinas apresenta uma abordagem alternativa dos direitos humanos que, sem subestimar os avanços positivos alcançados, evidencia a sua precariedade ao servirem mais como armas ideológicas do poder público do que estratégias de luta e ação. Dentre os paradoxos e teses que o autor trabalha, anota-se aqui, primeiramente, a compreensão de que o sujeito moderno só alcança sua humanidade quando adquire direitos políticos de cidadania e isso ocorre na medida em que pertenceria a um Estado-nação. Desta forma, haveria uma exclusão, que não se limitaria às pessoas que são ou estão fora do território nacional, como o refugiado, mas afetaria também àqueles indivíduos que não são reconhecidos pelos seus próprios Estados, como o caso dos moradores de favela, crianças em situação de rua, etc. ${ }^{14}$

O autor alerta ainda para a combinação entre um sistema econômico que gera enormes desigualdades estruturais e opressão com uma ideologia jurídico-política que promete dignidade e equidade, ou seja, cria-se um capitalismo neoliberal "aceitável” para um mundo de direitos humanos, situação que induz os países em desenvolvimento a uma falsa expectativa de também eles chegarem ao padrão econômico ocidental.

A promessa (implícita) para os países em desenvolvimento é de que a violenta ou voluntária adoção do modelo mercantilista e neoliberal de boa governança e direitos limitados irá inexoravelmente conduzir ao padrão econômico ocidental. Isto é fraudulento. Historicamente, a habilidade do ocidente para transformar a proteção de direitos formais numa limitada garantia de direitos materiais, econômicos e sociais estava baseada na enorme transferência das colônias para as metrópoles. Embora a moralidade universal militasse a favor da inversão de fluxos, a política ocidental de ajuda ao desenvolvimento e a dívida do Terceiro Mundo indicam que tal inversão não é politicamente viável. [...] Sistemas sociais e políticos tornam-se homogêneos ao transformarem suas prioridades ideológicas em valores e princípios universais [...] 0 desejo ainda está lá; as idéias foram redefinidas, mas a crença na universalidade da nossa visão de mundo permanece tão forte como a dos colonizadores. ${ }^{15}$

Douzinas sustenta também a tese de que há uma organização biopolítica que transforma os direitos humanos em ferramentas de controle do corpo social. "A biopolítica do poder é evidente em todos os fenômenos políticos importantes, tais como: a guerra contra o terror; a

\footnotetext{
${ }^{13}$ DOUZINAS, Costas. 0 paradoxo dos direitos humanos. Tradução de Caius Brandão. In: Pensar os Direitos Humanos: desafios à educação nas sociedades democráticas. Anuário do Núcleo Interdisciplinar de Estudos e Pesquisa em Direitos Humanos, UFG. Vol.1. n. 1, 2011.

${ }^{14}$ DOUZINAS, Costas. O Fim dos Direitos Humanos. São Leopoldo: UNISINOS, 2009.

${ }^{15}$ DOUZINAS, Costas. O Fim dos Direitos Humanos. São Leopoldo: UNISINOS, 2009. p. 24.
} 
A EFETIVAÇÃO DOS DIREITOS HUMANOS NA CONCEPÇÃO MULTICULTURAL: CONSTRUÇÃO DA CIDADANIA COSMOPOLITA

CRISNA MARIA MULLER DIRCEIA MOREIRA

migração em massa; as políticas para refugiados; as iniciativas de saúde pública; as políticas de segurança."16 0 biopoder é compreendido como o exercício do poder na bio, na vida, e esta intervenção atinge a existência coletiva dos grupos sociais especificados em termos de raça, etnia, religião ou gênero.

Desta forma, a concepção do discurso hegemônico ocidental dos direitos humanos tem nítida base estatal na visão neoliberal e sua ideologia provoca distorções no discurso e limita a prática e a tutela destes direitos. Giovanni Olsson assinala dois momentos distintos desta apropriação: o primeiro refere-se à conversão dos valores humanos em estruturas puramente formais, que tem no Estado seu único devedor; e o segundo momento é o da retirada dos meios de intervenção no mercado e na sociedade para orientar a economia a favor da maioria da população, “com isto, o debate em torno das necessidades humanas não é mais um debate econômico ou social ou político, mas puramente jurídico formal”. ${ }^{17}$

De outro norte, são reconhecidos avanços positivos na efetivação dos direitos humanos e a existência de um movimento de luta, que mobiliza milhões de pessoas e milhares de ONG's, que muitas vezes se expõe a grandes riscos, em defesa de classes sociais e grupos oprimidos, em muitos casos vitimizados pelos próprios Estados capitalistas autoritários. Assim, gradualmente, a partir destas lutas, frequentemente anticapitalistas, é que foram se desenvolvendo discursos e práticas contra-hegemônicos de direitos humanos, com propostas não ocidentais, que possibilitam diálogos interculturais em um projeto cosmopolita. ${ }^{18}$

Neste ínterim, para aprofundar o discurso hegemônico e contra-hegemônico dos direitos humanos, acerca-se dos quatro modos de produção da globalização que dão origem a quatro formas de produção da globalização, propostas por Boaventura de Sousa Santos, que define globalização como “o processo pelo qual determinada condição ou entidade local estende a sua influência a todo o globo e, ao fazê-lo, desenvolve a capacidade de designar como local outra condição social ou entidade rival". ${ }^{19}$

\footnotetext{
${ }^{16}$ DOUZINAS, Costas. O Fim dos Direitos Humanos. São Leopoldo: UNISINOS, 2009. p. 34.

17 OLSSON, Giovanni A apropriação liberal do discurso dos direitos humanos e uma nova hermenêutica de superação. Revista do Tribunal Regional do Trabalho da $15^{\mathrm{a}}$ Região, Campinas, n. 24, 2011, p. 7. Disponível em: <http://www.trt15.jus.br/escola_da_magistratura/Rev24Art6.pdf >. Acesso em: 20 jul. 2015.

18 SANTOS, Boaventura de Sousa. Direitos Humanos: o Desafio da Interculturalidade. Revista Direitos Humanos, Brasília, v.2, jul., 2009.

19 SANTOS, Boaventura de Sousa. Direitos Humanos: o Desafio da Interculturalidade. Revista Direitos Humanos, Brasília, v.2, jul., 2009.
} 


\section{(a)

A EFETIVAÇ̃̃O DOS DIREITOS HUMANOS NA CONCEPČ̃̃ MULTICULTURAL: CONSTRUÇÃO DA CIDADANIA COSMOPOLITA

Primeiramente, aponta como forma de globalização o localismo globalizado, que consistiria no processo pelo qual determinado fenômeno local é globalizado com sucesso, como o caso da transformação da língua inglesa em língua universalmente aceita, a globalização do fast food americano, etc.

A segunda forma, o autor chama de globalismo localizado, onde há um impacto específico de práticas transnacionais que imperam nas condições locais. Nesta prática, incluem-se os enclaves de comércio livre ou zonas francas, o dumping ecológico, onde ocorre a compra pelos países do Terceiro Mundo de lixos tóxicos produzidos nos países capitalistas centrais. Desta forma, ocorre uma divisão destas formas de globalização, cabendo aos países centrais os localismos globalizados, enquanto que aos países periféricos resta a escolha de globalismos localizados, sendo que ambos se enquadram na globalização de-cima-para-baixo, ou seja, a globalização hegemônica. ${ }^{20}$

A globalização é muitas coisas. Uma delas é a crescente interconexão que existe em assuntos políticos e econômicos, pelo qual o Estado-nação ou a sociedade nacional já não é a unidade exclusiva de interação social e comunicação. Outro significado, que é mais radical, é que a globalização é um novo jogo de poder mundial que implica redefinir as regras de poder entre os Estados-nação, o capital e os movimentos da sociedade civil. O capital foi o primeiro ator que abandonou a prisão do Estado-nação e desenvolveu novas estratégias de poder no espaço global. Os capitais são capazes de usar a tecnologia da informação para reorganizar a divisão da mão-de-obra em escala global e de usar mão-de-obra barata em todo o mundo como um recurso para maximizar os seus lucros. ${ }^{21}$

Em oposição, duas são também as formas de globalização de-baixo-para-cima, ou de globalização contra-hegemônica. Nestas se situa o cosmopolitismo, que promove diálogos interculturais e organizações alternativas na periferia do sistema mundial:

As atividades cosmopolitas incluem, entre outras, diálogos e organizações SulSul, organizações mundiais de trabalhadores (a Federação Mundial de Sindicatos e a Confederação Internacional dos Sindicatos Livres), filantropia transnacional Norte-Sul, redes internacionais de assistência jurídica alternativa, organizações transnacionais de direitos humanos, redes mundiais de movimentos feministas,

\footnotetext{
${ }^{20}$ SANTOS, Boaventura de Sousa. Direitos Humanos: o Desafio da Interculturalidade. Revista Direitos Humanos, Brasília, v.2, jul., 2009.

${ }^{21}$ BECK, Ulrich. Cosmopolitismo, um novo paradigma para as ciências sociais. Entrevista com Ulrich Beck. 2007. Disponível em: <http://www.ihu.unisinos.br/noticias/noticias-arquivadas/10685cosmopolitismo-um-novo-paradigma-para-as-ciencias-sociais-entrevista-com-ulrich-beck>. Acesso em: 11 jul. 2015, p. 10.
} 
A EFETIVAÇÃO DOS DIREITOS HUMANOS NA CONCEPÇÃO MULTICULTURAL: CONSTRUÇÃO DA CIDADANIA COSMOPOLITA

CRISNA MARIA MULLER DIRCEIA MOREIRA

organizações não governamentais (ONG's) transnacionais de militância anticapitalista, redes de movimentos e associações ecológicas e de desenvolvimento alternativo, movimentos literários, artísticos e científicos na periferia do sistema mundial em busca de valores culturais alternativos, não imperialistas, empenhados em estudos sob perspectivas pós-coloniais ou subalternas etc. ${ }^{22}$

Por fim, a quarta forma de globalização é o patrimônio comum da humanidade que diz respeito à emergência de temas que, pela sua natureza, só fazem sentido se tratados globalmente, tais como "a sustentabilidade da vida humana na Terra, por exemplo, ou temas ambientais como a proteção da camada de ozônio; a preservação da Amazônia, da Antártica, da biodiversidade [...] exploração do espaço exterior". ${ }^{23}$

Ambos os processos, o cosmopolitismo e o patrimônio comum da humanidade, tiveram um grande desenvolvimento nas últimas décadas e na mesma intensidade sofreram fortes resistências, sobretudo dos países hegemônicos. ${ }^{24}$

Ademais, para que os direitos humanos possam ser concebidos como cosmopolitismo ou globalização contra-hegemônica, eles não poderão ser concebidos como universais, pois assim tenderiam a operar como globalização de-cima-para-baixo sobre as culturas. A abrangência global dos direitos humanos, na perspectiva do cosmopolitismo, será obtida à custa da sua legitimidade local, onde estes direitos têm que ser reconceituados como multiculturais. ${ }^{25}$

Assim, o cosmopolitismo pode ser interpretado como a expressão da luta em defesa dos bens da humanidade, onde haja participação autônoma da pessoa ao atuar em movimentos, ONGs, associações, etc., “de dimensões transnacionais, criando perspectivas normativas comuns, um novo contrato social, para a vida partilhada num espaço-global, articulado por uma ética intercultural e pelo respeito à vida". ${ }^{26}$

Ulrich Beck sustenta o necessário fortalecimento de uma visão cosmopolita, uma vez que no atual contexto global as fronteiras geográficas ou territoriais, as fronteiras econômicas,

\footnotetext{
22 SANTOS, Boaventura de Sousa. Uma concepção multicultural de Direitos Humanos. Contexto Internacional,Rio de Janeiro, vol.23, jan/jun, 2001, p. 14.

${ }_{23}$ SANTOS, Boaventura de Sousa. Uma concepção multicultural de Direitos Humanos. Contexto Internacional, Rio de Janeiro, vol.23, jan/jun, 2001, p. 14.

${ }^{24}$ SANTOS, Boaventura de Sousa. Direitos Humanos: o Desafio da Interculturalidade. Revista Direitos Humanos, Brasília, v.2, jul., 2009.

${ }_{25}$ SANTOS, Boaventura de Sousa. Direitos Humanos: o Desafio da Interculturalidade. Revista Direitos Humanos, Brasília, v.2, jul., 2009.

26 WOLKMER, Maria de Fátima. Cidadania cosmopolita, ética intercultural e globalização neoliberal. Revista Sequiência. Florianópolis, n. 46, jul 2003, p. 47.
} 
A EFETIVAÇÃO DOS DIREITOS HUMANOS NA CONCEPÇÃO MULTICULTURAL: CONSTRUÇÃO DA CIDADANIA COSMOPOLITA

CRISNA MARIA MULLER DIRCEIA MOREIRA

culturais e políticas já não coincidem. As pessoas vivem em diferentes países ao mesmo tempo, diferentes identidades culturais ao mesmo tempo. Até mesmo os Estados precisam cooperar com os outros Estados para enfrentar os problemas como a mudança climática ou a situação do Estado de bem-estar. ${ }^{27}$

O cosmopolitismo supõe o surgimento de múltiplas lealdades, assim como o aumento de variadas formas de vida transnacionais, como a Anistia Internacional, a Organização Mundial do Comércio, etc., e o auge de movimentos de protestos globais contra a globalização econômica. Outrossim, com o cosmopolitismo, busca-se o reconhecimento internacional dos direitos humanos, o direito do trabalho, a proteção do meio ambiente, a supressão da pobreza, entre outros. $^{28}$

Neste contexto de convergência da diversidade de atores em movimento, em defesa de interesses comuns à humanidade, é que, segundo Wolkmer, é gestada a cidadania cosmopolita a partir de uma epistemologia dialógica e de uma ética-intercultural.

\begin{abstract}
Diante disso, o que se requer é uma nova ética global, que reconheça o dever de cuidar, além das fronteiras, bem como dentro delas, de uma nova negociação global entre nações ricas e pobres. Isso implica repensar a democracia social e a cidadania como um projeto nacional, reconhecendo que, para continuar eficazes num mundo que se globaliza, ambas tem que estar inseridas num sistema reformulado e muito mais forte de gestão global, que procure combinar a segurança humana com a eficiência econômica. Entender as possibilidades que se abrem nos processos de Globalização para o fortalecimento da democracia e da consolidação de "espaços de encontro", objetivando uma cidadania cosmopolita, exige um esforço analítico para ampliar a reflexão jurídico-política. ${ }^{29}$
\end{abstract}

No entanto, Andrade alerta para a existência da configuração hegemônica também do discurso da cidadania consolidada pelo sistema capitalista, na qual o exercício da cidadania é resumido à titularidade dos direitos civis, políticos, econômicos e sociais, garantidos, em tese, pela igualdade jurídica. Deste modo, é necessário o emprego de cautela quando o discurso da cidadania contiver a pretensão à universalização, pois a cidadania não se aplica de forma igual em todo tempo e lugar, mas sim cria tratamento jurídico e práticas sociais diferentes em situações diferentes. "Ou seja, não se trata de afirmar que existem direitos de cidadania

27 BECK, Ulrich. O Estado cosmopolita: Para uma utopia realista. 2002. Disponível em: <www.eurozine.com>. Acesso em: 10 ago. 2015.

28 BECK, Ulrich. O Estado cosmopolita: Para uma utopia realista. 2002. Disponível em: <www.eurozine.com>. Acesso em: 10 ago. 2015.

29 WOLKMER, Maria de Fátima. Cidadania cosmopolita, ética intercultural e globalização neoliberal. Revista Sequiência. Florianópolis, n. 46, jul 2003, p. 31. 
A EFETIVAÇÃO DOS DIREITOS HUMANOS NA CONCEPÇÃO MULTICULTURAL: CONSTRUÇÃO DA CIDADANIA COSMOPOLITA

CRISNA MARIA MULLER DIRCEIA MOREIRA

formalmente iguais para indivíduos concretamente diferentes. Mas existem direitos de cidadania formalmente desiguais para indivíduos desiguais". ${ }^{30}$

Em contrapartida, deve haver espaço para o discurso heterogêneo de cidadania, uma vez que o próprio direito ao discriminar tratamento jurídico diversificado aos diferentes indivíduos, como os trabalhadores, mulheres, índios, acaba por criar múltiplas formas e fontes de cidadania e provoca o deslocamento da construção individual da cidadania para a coletiva quando articula as classes sociais. ${ }^{31}$

Ulrich Beck aponta para os migrantes como atores que contribuem significativamente com a construção do cosmopolitismo, mesmo sem o pretender diretamente, são eles que forçam o cosmopolitismo porque são os que acumulam conhecimento para saber como interagir entre as fronteiras e usam as diferenças nas regulações e nas culturas para construir sua própria forma de vida. Logo, esses migrantes-imigrantes modificam as fronteiras, misturam as línguas, as leis, os sistemas, ou seja, são os que estão construindo espaços transnacionais para viver e atuar. Desta forma, surge um novo paradigma do futuro, que coloca em cena o modelo de cosmopolitismo. ${ }^{32}$

É nesse sentido, a preocupação de se desenvolver articulações que tratem de mediar as relações entre culturas locais e culturas globais, a partir de uma perspectiva de inclusão daquele que é diferente, que possui uma identidade ou cultura distinta daquele grupo cultural em que se busca inserir. Isto porque, nas sociedades atuais, como afirmou Cortina, é preciso:

[...] gerar entre seus membros um tipo de identidade na qual se reconheçam e que os faça se sentir pertencentes a elas, porque é evidente que esse tipo de sociedade sofre de uma falta de adesão por parte dos cidadãos ao conjunto da comunidade aos desafios que se apresentam a todos. ${ }^{33}$

Assim, a cidadania cosmopolita é entendida para além da soma dos diferentes grupos ou culturas, é sim pressuposto de uma nova forma de ver o mundo e de se relacionar com o outro. “Essas práticas já estão ocorrendo na sociedade civil local, nacional, regional e global e

\footnotetext{
${ }^{30}$ ANDRADE, Vera Regina Pereira de. Cidadania: do direito aos direitos humanos. São Paulo: Acadêmica, 2003, p. 69.

${ }^{31}$ ANDRADE, Vera Regina Pereira de. Cidadania: do direito aos direitos humanos. São Paulo: Acadêmica, 2003.

32 BECK, Ulrich. Cosmopolitismo, um novo paradigma para as ciências sociais. Entrevista com Ulrich Beck. 2007. Disponível em: <http://www.ihu.unisinos.br/noticias/noticias-arquivadas/10685cosmopolitismo-um-novo-paradigma-para-as-ciencias-sociais-entrevista-com-ulrich-beck>. Acesso em: 11 jul. 2015.

${ }_{33}^{33}$ CORTINA, Adela. Cidadãos do Mundo: para uma teoria da cidadania. SP: Loyola, 2005, p. 18.
} 


\section{每

A EFETIVAÇÃO DOS DIREITOS HUMANOS NA CONCEPÇÃO MULTICULTURAL: CONSTRUÇÃO DA CIDADANIA COSMOPOLITA

CRISNA MARIA MULLER DIRCEIA MOREIRA

representam a articulação de uma nova cidadania que investe na invenção de novas possibilidades de vida diante da globalização neoliberal e todas as formas de exclusão" ${ }^{34}$

O conceito de cidadania dentro de uma visão intercultural, onde se busca dar respostas para as necessidades específicas de grupos minoritários, deve ser construído levando-se em consideração as diferenças existentes, uma vez que os direitos de cidadania originalmente foram definidos por e para os homens brancos. ${ }^{35}$

Logo, a cidadania se estende para além das fronteiras do Estado Nacional, onde pertencer por nascimento ou raça a uma nação é menos importante do que estar ligados e lutar por projetos comuns. Trata-se de uma experiência humana de unidade na terra, que abre caminhos para valores e elementos comuns na formação do cidadão cosmopolita.

Sendo assim, os elementos se entrecruzam na formação do que, hoje, poderia ser considerado um cidadão cosmopolita são: diálogo, participação, respaldo em leis e instituições regionais e globais (ainda insuficientes), ética intercultural (a unidade na diferença), solidariedade frente a todas as formas de exclusão, e um projeto comum para a humanidade, cujo núcleo venha a ser o respeito à vida. ${ }^{36}$

Deste modo, a abertura do diálogo entre as culturas, com base no respeito à diversidade e no reconhecimento do outro, como pleno de dignidade e direitos, é condição para a celebração de uma cultura dos direitos humanos.

A fim de se admitir os direitos humanos como instrumento para o cosmopolitismo, afastando-os de seu uso hegemônico, Boaventura de Sousa Santos propõe o preenchimento de cinco premissas. Inicialmente, deve-se superar o debate entre universalismo e relativismo cultural:

Trata-se de debate intrinsecamente falso, cujos conceitos polares são igualmente prejudiciais para uma concepção emancipatória de direitos humanos. Todas as culturas são relativas, mas o relativismo cultural enquanto atitude filosófica é incorreto. Todas as culturas aspiram preocupações e valores universais, mas o universalismo cultural, enquanto atitude filosófica é incorreto. Contra o universalismo, há que propor diálogos interculturais sobre preocupações isomórficas. Contra o relativismo, há que desenvolver critérios políticos para

\footnotetext{
34 WOLKMER, Maria de Fátima. Cidadania cosmopolita, ética intercultural e globalização neoliberal. Revista Sequiência, Florianópolis, n. 46, jul 2003, p. 32.

35 WOLKMER, Maria de Fátima. Cidadania cosmopolita, ética intercultural e globalização neoliberal. Revista Sequiência, Florianópolis, n. 46, jul 2003.

36 WOLKMER, Maria de Fátima. Cidadania cosmopolita, ética intercultural e globalização neoliberal. Revista Sequiência, Florianópolis, n. 46, jul 2003, p. 47.
} 
A EFETIVAÇÃO DOS DIREITOS HUMANOS NA CONCEPÇÃO MULTICULTURAL: CONSTRUÇÃO DA CIDADANIA COSMOPOLITA

CRISNA MARIA MULLER DIRCEIA MOREIRA

distinguir política progressista de política conservadora, capacitação de desarme, emancipação de regulação. ${ }^{37}$

A segunda premissa é o reconhecimento de que todas as culturas possuem concepções de dignidade humana, mas nem todas no contexto dos direitos humanos. A terceira e a quarta premissa afirmam que todas as culturas são incompletas e problemáticas na sua concepção de dignidade humana, porém apresentam graus de reciprocidade diferenciados, devendo-se preferir aqueles que apresentam um círculo mais alargado de reconhecimento de direitos. Por fim, a quinta é a de que as culturas distribuem as pessoas e os grupos sociais na hierarquia, utilizando o princípio da igualdade e o da diferença. ${ }^{38}$

Nesta perspectiva da construção do diálogo pautado pela ética intercultural e solidariedade universal, a filósofa espanhola Adela Cortina apresenta pressupostos que devem ser observados pelos indivíduos envolvidos no diálogo, quais sejam: 1) No diálogo devem participar os que são afetados pela decisão ou serem representados em seus interesses; 2) Quem leva o diálogo a sério não pode iniciá-lo convencido de que o interlocutor nada tem a contribuir, mas deve estar disposto a escutá-lo; 3) Isso significa que sabe que não está de posse de toda a verdade; 4) Estar disposto a escutar tanto para manter sua posição, se não the convencerem os argumentos do interlocutor, como para modificá-la caso o convençam; 5) Ter a preocupação em encontrar uma solução justa; 6) Exige que todos os interlocutores possam expressar seus pontos de vista, colocar seus argumentos, replicar as outras intervenções; 7) A decisão final pode estar equivocada e por isso sempre deve estar aberta a revisões. ${ }^{39}$

Assim, a percepção da importância do diálogo constrói-se, na visão cosmopolita, com o valor da solidariedade universal, “que acontece quando as pessoas atuam pensando não só no interesse particular dos membros de um grupo, senão também de todos os afetados pelas ações do grupo". ${ }^{40}$ Neste sentido, para Adela Cortina ${ }^{41}$ a solidariedade significa ultrapassar as fronteiras dos grupos e dos países, estendendo-se a todos os seres humanos, incluindo as gerações futuras. Com base na solidariedade universal e na ética intercultural seria perceptível

37 SANTOS, Boaventura de Sousa. Uma concepção multicultural de Direitos Humanos. Contexto Internacional, Rio de Janeiro, vol.23, jan/jun, 2001, p. 18.

38 SANTOS, Boaventura de Sousa. Uma concepção multicultural de Direitos Humanos. Contexto Internacional, Rio de Janeiro, vol.23, jan/jun, 2001.

${ }^{39}$ CORTINA, Adela. Cidadãos do Mundo: para uma teoria da cidadania. SP: Loyola, 2005.

40 WOLKMER, Maria de Fátima. Cidadania cosmopolita, ética intercultural e globalização neoliberal. Revista Sequiência. Florianópolis, n. 46, jul 2003, p. 35.

${ }^{41}$ CORTINA, Adela. Cidadãos do Mundo: para uma teoria da cidadania. SP: Loyola, 2005. 


\section{(a)

A EFETIVAÇÃO DOS DIREITOS HUMANOS NA CONCEPÇÃO MULTICULTURAL: CONSTRUÇÃO DA CIDADANIA COSMOPOLITA

o surgimento de ao menos três novos valores: a paz, o desenvolvimento dos povos menos favorecidos e o respeito ao meio ambiente.

A ética intercultural por sua vez implica no respeito à diferença cultural, que possibilita à sociedade global buscar coisas diferentes entre si, sem encontrar nisso uma contradição, pois, o contrário da igualdade não é a diferença, mas a desigualdade. Assim, Boaventura de Sousa Santos propõe um imperativo intercultural, ou seja, "as pessoas e os grupos sociais têm o direito a serem iguais, quando a diferença os inferioriza, e o direito a serem diferentes, quando a igualdade os descaracteriza". ${ }^{42}$

Frente a estas leituras, o “mundo contemporâneo não é um mundo de comunidades fechadas, com modos de pensar mutuamente impenetráveis, economias auto-suficientes e Estados idealmente soberanos". ${ }^{43}$ Logo, não há razão para que os valores de determinadas comunidades políticas se sobreponham sobre os princípios globais, assim, não é contraditório que se busque um marco para a existência da cidadania cosmopolita e da ética intercultural.

Desta forma, na visão intercultural, conceito de cidadania deve levar em conta as diferenças e as necessidades específicas de cada cultura e grupo minoritário. Cortina, afirma que a cidadania cosmopolita poderá ser implementada por meio de:

projetos realistas, que partam daquilo que já faz parte da pessoa, podem ter êxito, e o ideal cosmopolita está latente no reconhecimento de direitos aos refugiados, na denúncia de crimes contra a humanidade, na necessidade de um Direito Internacional, nos organismos internacionais e, sobretudo, na solidariedade de uma sociedade civil, capaz de ultrapassar todas as barreiras. ${ }^{44}$

Assim, a cidadania cosmopolita, segundo Boaventura de Sousa Santos não conduzirá a novos modelos hegemônicos, mas a uma universalidade surgida do respeito à diversidade e de coexistência das culturas na sociedade civil global. ${ }^{45}$

Corroborando com este entendimento, o autor Liszt Vieira afirma que há vários níveis por meio dos quais pode ser concebida a extensão da cidadania, além das fronteiras tradicionais do Estado Nacional. Em primeiro lugar, "trata-se de uma aspiração ligada ao sentimento de unidade

42 SANTOS, Boaventura de Sousa. Reinventar a democracia: Entre o pré-contratualismo e o póscontratualismo. In: OLIVEIRA, Francisco de e PAOLI, Maria Célia (Org.) Os Sentidos da Democracia: Políticas do discurso e hegemonia global. Petrópolis: Vozes, 1999, p. 122.

43 WOLKMER, Maria de Fátima. Cidadania cosmopolita, ética intercultural e globalização neoliberal. Revista Sequiência, Florianópolis, n. 46, jul 2003, p. 37.

${ }_{44}^{44}$ CORTINA, Adela. Cidadãos do Mundo: para uma teoria da cidadania. SP: Loyola, 2005, p. 252.

45 SANTOS, Boaventura de Sousa. Uma concepção multicultural de Direitos Humanos. Contexto Internacional, Rio de Janeiro, vol.23, jan/jun, 2001. 
A EFETIVAÇÃO DOS DIREITOS HUMANOS NA CONCEPÇÃO MULTICULTURAL: CONSTRUÇÃO DA CIDADANIA COSMOPOLITA

CRISNA MARIA MULLER DIRCEIA MOREIRA

da experiência humana na terra e que abre caminho a valores e políticas em defesa da paz, justiça social, diversidade cultural, democracia e sustentabilidade ambiental em nível planetário." 46 Em segundo lugar, “diz respeito ao processo objetivo de globalização, que está promovendo uma integração global, especialmente econômica, enfraquecendo o Estado-nação e corroendo a cidadania nacional." Por último, é "o relativo consenso na opinião pública de que, no que diz respeito à energia e aos recursos naturais, a vida da espécie humana pode estar ameaçada se não forem efetuadas mudanças nos padrões de consumo e produção em nível global." 47

Reconceituar os direitos humanos como multiculturais é a forma de efetivar os direitos humanos como cosmopolitismo, de globalização de-baixo-para-cima. 0 reconhecimento do multiculturalismo é "precondição de uma relação equilibrada e mutuamente potenciadora entre a competência global e a legitimidade local, que constituem os dois atributos de uma política contra-hegemônica de direitos humanos no nosso tempo". ${ }^{48}$ Assim, a abrangência global dos direitos humanos só poderá ser obtida à custa da legitimação local.

Para isso, o caminho proposto é o da construção de uma nova identidade cívica mundial, que ultrapasse as diferenças nacionais e culturais, consolidando uma identidade cívica mundial. Enfim, "cabe à cidadania cosmopolita, no espaço intercultural da sociedade civil global reclamar para que todos os seres humanos tenham seus direitos econômicos, sociais e culturais garantidos". ${ }^{49}$

\section{CONCLUSÃO}

O debate contemporâneo em torno dos direitos humanos une os pressupostos teóricos de diferentes áreas e também o subjetivismo do cidadão globalizado das distintas culturas. 0 discurso hegemônico liberal dos direitos humanos expõe suas limitações ao pretender se apresentar como o caminho para a emancipação do ser humano global quando inserido numa

\footnotetext{
${ }^{46}$ VIEIRA, Liszt. Os argonautas da cidadania: a sociedade civil na globalização. Rio de Janeiro: Record, 2001, p. 263.

47 VIEIRA, Liszt. Os argonautas da cidadania: a sociedade civil na globalização. Rio de Janeiro: Record, 2001, p. 263.

48 SANTOS, Boaventura de Sousa. Uma concepção multicultural de Direitos Humanos. Contexto Internacional, Rio de Janeiro, vol.23, jan/jun, 2001, p. 15-16.

49 WOLKMER, Maria de Fátima. Cidadania cosmopolita, ética intercultural e globalização neoliberal. Revista Sequiência, Florianópolis, n. 46, jul 2003, p. 45.
} 
A EFETIVAÇÃO DOS DIREITOS HUMANOS NA CONCEPÇÃO MULTICULTURAL: CONSTRUÇÃO DA CIDADANIA COSMOPOLITA

CRISNA MARIA MULLER DIRCEIA MOREIRA

cultura específica, pois este discurso é apropriado e colocado a serviço dos interesses econômicos e geo-políticos dos Estados capitalistas hegemônicos.

O reconhecimento deste cenário internacional conduz à busca de uma nova hermenêutica dos direitos humanos, fundada no mínimo ético da cidadania cosmopolita, com propostas não ocidentais, espaços públicos de mediação e encontro entre as diversas culturas, movimentos de luta, que mobilizam milhões de pessoas e infinidade de instituições em defesa de classes sociais e grupos oprimidos, como é o caso dos refugiados e migrantes na atualidade.

Nesta perspectiva, a cidadania cosmopolita tem seu processo iniciado na produção de uma subjetividade, na emergência do modo de ser ético, em que o cidadão cosmopolita é reconhecido por alguns elementos como o diálogo, participação, respeito ao multiculturalismo, solidariedade frente às formas de exclusão, além da inserção em um projeto comum para a humanidade, que busca assegurar, no interior e além das fronteiras nacionais, uma vida digna para todos.

Apesar dos direitos humanos, por um lado, continuarem a ter uma decisiva dimensão nacional e ser observada a fragilidade dos sistemas e mecanismos internacionais em garanti-los, tem-se que, por outro lado, já se encontram assentados em pressupostos culturais específicos, que necessitam ser fortalecidos, para que os direitos humanos sejam efetivados em uma dimensão multicultural.

\section{REFERÊNCIAS}

ANDRADE, Vera Regina Pereira de. Cidadania: do direito aos direitos humanos. São Paulo: Acadêmica, 2003.

BARROSO, Marcela Giorgi. Multiculturalismo e Direito Internacional. In: Âmbito Jurídico, Rio Grande, n. 58, 2008. Disponível em: <http://www.ambito-

juridico.com.br/site/index.php?n_link=revista_artigos_leitura\&artigo_id=5230>. Acesso em: 21 jul.2015.

BECK, Ulrich. O Estado cosmopolita: Para uma utopia realista, 2002. Disponível em: <www.eurozine.com>. Acesso em: 10 ago.2015.

. Cosmopolitismo, um novo paradigma para as ciências sociais. Entrevista com Ulrich Beck. Instituto Humanistas Unisinos, 2007. Disponível em: <http://www.ihu.unisinos.br/noticias/noticias-arquivadas/10685-cosmopolitismo-um-novoparadigma-para-as-ciencias-sociais-entrevista-com-ulrich-beck>. Acesso em: 11 jul. 2015. 


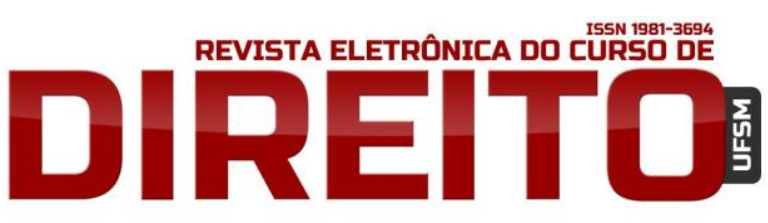

A EFETIVAÇÃO DOS DIREITOS HUMANOS NA CONCEPCCÃO MULTICULTURAL: CONSTRUÇÃO DA CIDADANIA COSMOPOLITA

BOBBIO, Norberto. A era dos direitos. Tradução de Carlos Nelson Coutinho. Rio de Janeiro: Campus, 2004.

CORTINA, Adela. Cidadãos do Mundo: para uma teoria da cidadania. São Paulo: Loyola, 2005.

DOUZINAS, Costas. O paradoxo dos direitos humanos. Tradução de Caius Brandão. In: Pensar os Direitos Humanos: desafios à educação nas sociedades democráticas. Anuário do Núcleo Interdisciplinar de Estudos e Pesquisa em Direitos Humanos - UFG. Vol.1. n. 1, 2011. Disponível em:

<http://www.cienciassociais.ufg.br/up/106/o/ConferenciaAberturax.pdf?1350490879 >. Acesso em: 7 ago.2015.

. O Fim dos Direitos Humanos. São Leopoldo: Unisinos, 2009.

MPF. Declaração Francesa dos Direitos do Homem e do Cidadão de 1789. Disponível em http: <http://pfdc.pgr.mpf.mp.br/atuacao-e-conteudos-de-apoio/legislacao/direitoshumanos/declar_dir_homem_cidadao.pdf >. Acesso em: 10 mar. 2016.

OLSSON, Giovanni A apropriação liberal do discurso dos direitos humanos e uma nova hermenêutica de superação. Revista do Tribunal Regional do Trabalho da $15^{\text {a }}$ Região, Campinas, n. 24, 2011. Disponível em:

<http://www.trt15.jus.br/escola_da_magistratura/Rev24Art6.pdf >. Acesso em: 20 jul.2015.

PIOVESAN, Flávia. Direitos humanos e o direito constitucional internacional. 8.ed. São Paulo: Saraiva, 2007.

SANTOS, Boaventura de Sousa. Uma concepção multicultural de Direitos Humanos. Revista Contexto Internacional, Rio de Janeiro, vol.23, jan/jun, 2001, p.7-34.

.Direitos Humanos: o

Desafio da Interculturalidade. Revista Direitos Humanos, Brasília, v.2, jul., 2009. Disponível em:

<http://www.boaventuradesousasantos.pt/media/Direitos\%20Humanos_Revista\%20Direitos\%20Hu manos2009.pdf>. Acesso em: 8 mar.2016.

- Reinventar a democracia: Entre o pré-contratualismo e o pós-

contratualismo. In: OLIVEIRA, Francisco de e PAOLI, Maria Célia (Org.) Os Sentidos da

Democracia: Políticas do discurso e hegemonia global. Petrópolis: Vozes, 1999.

SARLET, Ingo Wolfgang. A eficácia dos direitos fundamentais. 10. ed. Porto Alegre: Livraria do Advogado, 2008.

RIBAS DO NASCIMENTO, Valéria. Direitos humanos e constitucionalisno na perspectiva cosmopolita: um e outro diante do espelho. Estudios Avanzados: Issue, 2011. 
ISSN 1981-3694

(DOI): $10.5902 / 1981369419730$ REVISTA ELETRÔNICA DO CURSD DE

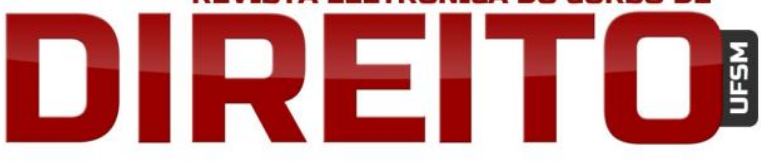

A EFETIVAÇÃO DOS DIREITOS HUMANOS NA CONCEPÇÃO MULTICULTURAL: CONSTRUÇÃO DA CIDADANIA COSMOPOLITA

CRISNA MARIA MULLER DIRCEIA MOREIRA

VIEIRA, Oscar Vilhena. Reflexões acerca da sociedade civil e dos direitos humanos. São Paulo: Conectas Direitos Humano, Ed. v. 1, n. 1, Jan/2004.

Disponível em: <http://www.conectas.org/pt/acoes/sur/edicao/1/1000229-reflexoes-acercada-sociedade-civil-e-dos-direitos-humanos >. Acesso em: 15 mar. 2016.

VIEIRA, Liszt. Os argonautas da cidadania: a sociedade civil na globalização. Rio de Janeiro: Record, 2001.

WOLKMER, Maria de Fátima. Cidadania cosmopolita, ética intercultural e globalização neoliberal. Revista Sequiência: Florianópolis, n. 46, jul 2003, p. 29-49.

Recebido em: 01.10.2015 / Revisões requeridas em: 02.03.2016/ Aprovado em: 22.03.2016 